\title{
Faecal Carriage Rate of Extended-Spectrum Beta- Lactamase-Producing Escherichia coli and Klebsiella Pneumonia Among Apparently Health Food Handlers in Dilla University Student Cafeteria
}

Kuma Urgeya Diriba ( $\square$ kumadiriba47@gmail.com )

Dilla University https://orcid.org/0000-0002-7083-7725

Ephrem Awulachew

Dilla University

Lami Takele

Dilla University

Zemachu Ashuro

Dilla University

\section{Research}

Keywords: Extended-spectrum $\beta$-lactamase, Enterobacteriaceae, antibiotic resistance, Klepsiella pneumonia, Escherichia coli, Ethiopia

Posted Date: September 2nd, 2020

DOl: https://doi.org/10.21203/rs.3.rs-69223/v1

License: (c) (i) This work is licensed under a Creative Commons Attribution 4.0 International License. Read Full License 


\section{Abstract}

Background: The rapid spread of extended-spectrum $\beta$ - lactamases (ESBL) producing enterobacteriaceae among food handlers, which can cause food borne outbreaks, is a public health concern and become a serious world threat. Klebsiella pneumoniae and Escherichia coli are the predominant ESBL-producing enterobacteriaceae. There is no sufficient data related to this in underdeveloped countries.

Objective: This study was aimed assess the magnitude of ESBL producing Klebsiella pneumoniae and Escherichia coli isolated from stool of apparently health food handlers in the Dilla University Student Cafeteria.

Methods: A cross-sectional study was conducted from November to September 2018/2019. A structured questionnaire was used for collection of data on socio- demographics. A total of 220 stool samples were cultured on MacConkey agar and a series of biochemical tests was done for the identification of bacterial species. Double-disk synergy (DDS) method was used for the detection of ESBL-producing strains. A disc of amoxicillin clavulanic acid was placed in the center of the Mueller-Hinton agar plate, and cefotaxime, aztreonam, and ceftazidime were placed at a distance of $20 \mathrm{~mm}$ from the disk placed at center. Enhanced inhibition zone of any of the cephalosporin discs on the side facing amoxicillin clavulanic acid was considered as ESBL producer.

Results: The rate of faecal carriage of E. coli and K. pneumonia among the food handlers of the current study was found to be $66.4 \%$, of which $81.5 \%$ was E. coli, while $18.5 \%$ was K. pneumonia. From the total bacterial isolates, $25.3 \%$ were confirmed to be positive for ESBL production of which $19.9 \%$ was E. coli, while $5.5 \%$ was K. pneumonia. ESBL-producing faecal carriage showed high resistance to aztreonam, cefotaxime, ceftriaxone, cefuroxime, and ceftazidime with resistance rate ranged from $88-100 \%$, while the least resistance rate was seen against imipenem accounted $<26.3 \%$. In this study, around $91.9 \%$ of ESBLproducing isolates were co-resistant to $\beta$-lactams antibiotics plus at least one of the non $\beta$-lactam antibiotics. Only food handlers who used antibiotics repeatedly in the last 3 months were significantly associated with the ESBL carriage with $\mathrm{P}$ values of $0.001,95 \% \mathrm{Cl}(1.12-3.18)$.

Conclusion: The magnitude of ESBL-producing E. coli and K. pneumonia faecal carriage is alarmingly high and a threat to human health. The occurrence of multidrug resistance to third-generation cephalosporins and non- $\beta$ lactam antibiotics is more common among ESBL producers. Detecting and reporting of ESBLproducing organisms have a remarkable importance in clinical decision-making. Hence, a coordinated effort should be implemented for the prevention and control the disease Enterobacteriaceae

\section{Background}

The Enterobacteriaceae are a substantial, heterogeneous group of gram-negative rods whose natural habitat is the intestinal tract of human beings and animals (1). These microorganisms have emerged as one of the most important reasons for nosocomial and community-obtained infections (2-5). Enterobacteriaceae are typically associated with a range of infections (6), among which urinary tract 
infections, bloodstream infections, heath facility associated pneumonia, and some of the intra-abdominal infections are the most crucial $(7,8)$. Studies conducted in different underdeveloped countries indicate that a high case-fatality rate associated with bloodstream infection due to Enterobacteriaceae $(9,10)$.

Antibiotics play a vital role in decreasing the load of communicable diseases all around the world (11). Microbial resistance to antimicrobial agents is remarkably rising globally (12-14). This rapid spread of resistance among pathogenic microorganisms is a serious problem globally $(2,4)$, because it limits the drug treatment alternative against infections (15). Antimicrobial resistance has presently been recognized as one of the most important problems facing human health by the World Health Organization (WHO) (15, 16). Frequent isolation of multidrug resistant (MDR) pathogens in both hospital and community acquired infections further intensified the problem of antimicrobial resistance (5).

Now a days extended-spectrum $\beta$ - lactamases (ESBLs) producing Klebsiella pneumoniae and Escherichia coli is a serious public health issue globally (1). They become resistance to beta-lactam antibiotics via the production of beta-lactamases enzymes which inactivate beta-lactam antibiotics and this continues to be the prominent cause of $\beta$-lactam antibiotics resistance among Enterobacteriaceae $(17,18)$. It can rapidly develop resistance against a range of important broad-spectrum antimicrobials $(19,20)$. Inappropriate and irrational use of antimicrobial drugs, poor sanitary and infection control practices in developing countries play a critical role in an increased prevalence of resistant bacteria in a community provides favorable conditions for resistant microorganisms to emerge and spread $(21,22)$. This can lead to a proliferation of organisms with broad-spectrum $\beta$-lactamase activity that threatens the future of the $\beta$-Lactam class in clinical care (21).

The increasing rate of human infections caused by anti-microbial resistance strains of Enterobacteriaceae makes clinical management more difficult by prolonging the illness and compromise the treatment (5). This can have a potentially serious impact on human health. The situation is more common in developing countries where there is widespread and uncontrolled use of antibiotics (16). Data on extended-spectrum $\beta$ - lactamases producing Enterobacteriaceae in Ethiopia are limited and there is no data associated with this. Therefore, this study was aimed assess the magnitude of ESBL producing Klebsiella pneumoniae and Escherichia coli isolated from stool of apparently health food handlers in the Dilla University Student Cafeteria.

\section{Methods}

\section{Study design and period}

An institutional-based cross-sectional study was carried out among food handlers to evaluate the magnitude and antimicrobial resistance pattern of ESBL-producing E. coli and K. pneumoniae from stools of apparently health food handlers in Dilla University Student Cafeteria, Southern Ethiopia from November 2018 to September 2019. Three sample selection sites were identified prior to data collection. To select representative participants, the final sample size was proportionally allocated to each stratum, and food 
handlers were selected using a systematic random sampling technique. Finally, a total of 220 were included in the study based on the single population proportion formula.

\section{Data collection and analysis}

Data related to socio-demographic characteristics and personal hygiene practices were collected via face to face interviewing of the patient or guardian of the patient by using a well-structured questionnaire before laboratory sample collection. One environmental health and four medical laboratory professionals were recruited for data collection, supervision, and microbiological analysis. The data collectors were trained for 2 days by the principal investigator on observational data collection and specimen collection procedures.

\section{Laboratory Data Collection and analysis}

After interviewing, all respondents were asked to give a fresh stool specimen in a sterile, clean widemouthed plastic, and leak proof container by a clean wooden applicator stick for microbiological analysis. The isolation and characterization of $E$. coli and $K$. pneumoniae were performed based on the standard procedure. Briefly, a mixture of a stool sample $(1 \mathrm{~mL})$ was transferred to the selective media, Hicrome ESBL agar base, to assess the ESBL production in $2 \mathrm{hr}$ (Oxoid, Ltd UK). An inoculum from Hicrome ESBL agar base was cultured onto MacConkey agar (Oxoid, Ltd UK). After overnight incubation at $37^{\circ} \mathrm{C}$ the growth of E. coliand K. pneumoniae was differentiated by their colony characteristic, pigment production (pink to colorless flat or mucoid colonies), motility and Gram-staining techniques (Gram-negative rods, non-sporing, and non-capsulated).

A list of biochemical tests conducted for further identification of isolates were made by conformation of motility and other relevant biochemical tests. An isolate was considered as $\mathrm{E}$. coli when it is indole positive(dark pink ring) and methyl-red positive, citrate negative (no change or remained green) and urea negative, gas and acid producer, and motile and wasconsidered as K. pneumoniae when it is indole and methyl-red negative, citrate positive, urea slow producing, and non-motile. In case of delay, the isolated bacteria were kept at $2-8{ }^{\circ} \mathrm{C}$ in the nutrient broth for not more than 24 hours until the antimicrobial sensitivity test was done.

\section{Detection method of ESBL-producing $E$. coli and $K$. pneumonia}

Disk-diffusion method was used to screen ESBL producer using ceftazidime (30 $\mu g)$, cefotaxime (30 $\mu g)$, and ceftriaxone (30 $\mu g$ ) (Oxoid, UK) as per CLSI criteria. A suspension of pure colony was wrapped on Mueller-Hinton agar (MHA) (Oxoid, UK) with a sterile cotton swab, and antibiotics discs were placed at a distance of $20 \mathrm{~mm}$ from each other and incubated at $35 \pm 2{ }^{\circ} \mathrm{C}$ for $16-18$ hours. The isolates with diminished susceptibility with breakpoint of $\leq 22 \mathrm{~mm}$ for ceftazidime, $\leq 25 \mathrm{~mm}$ for ceftriaxone, and $\leq$ $27 \mathrm{~mm}$ for cefotaxime were suspicion for ESBL production (15). Phenotypic Confirmations of ESBL 
producers was performed using double disc synergy between the indicator cephalosporin and clavulanic acid, according to EUCAST guidelines (23). A disc of amoxicillin/clavulanic acid (20/10 $\mu g)$ was placed in the center of the MHA plate, and then cefotaxime $(30 \mu \mathrm{g})$, ceftazidime $(30 \mu \mathrm{g})$ and aztreonam $(30 \mu \mathrm{g})$ were placed at a distance of $20 \mathrm{~mm}$ edge to edge from the amoxicillin/clavulanic acid disk. After 24hours incubation, the elevation of $\geq 5 \mathrm{~mm}$ zone inhibition between either of the cephalosporin disks and their respective amoxicillin/clavulanic acid disks was interpreted as ESBL producer (24) (Fig. 1)

\section{Antimicrobial Susceptibility Testing}

Antimicrobial susceptibility tests were performed for both Enterobacteriaceae by using the disc diffusion technique on Mueller-Hinton agar based on EUCAST guidelines (23) for the listed antibiotics: Ampicillin $(10 \mu \mathrm{g})$, aztreonam $(30 \mu \mathrm{g})$, cefotaxime $(30 \mu \mathrm{g})$, ceftriaxone $(30 \mu \mathrm{g})$, ceftazidime $(30 \mu \mathrm{g})$, cefoxitin $(30 \mu \mathrm{g})$ cefuroxime $(30 \mu \mathrm{g})$, ciprofloxacin $(5 \mu \mathrm{g})$, nitrofurantoin (300 $\mu \mathrm{g})$, trimethoprim-sulfamethoxazole $(1.25 / 23.75 \mu g)$, tetracycline $(30 \mu g)$ and imipenem (30 $\mu$ ) (all from Oxoid; UK). The resistance and sensitivity results were interpreted according to the EUCAST guidelines (23). MDR was defined as acquired non-susceptibility to at least one agent in three or more antimicrobial categories. The quality and performance of culture media, biochemical tests, and antimicrobial susceptibility discs were checked using a control strain (E. coli ATCC 25922 and K. pneumoniae ATCC 700603) obtained from Ethiopian Public Health Institute, Addis Ababa.

\section{Data Analysis}

The descriptive statistical analysis was performed by using SPSS version 24 software. The prevalence of ESBL producers and non- ESBL-producing isolates were categorized by personal hygiene related factors of food handlers and presented by calculating frequencies and percentages. Chi-square test was used with appropriate correction for the observation. Multivariate logistic regression analysis was used to identify risk factors for colonization by ESBL. P values $<0.05$ were considered statistically significant.

\section{Ethical consideration}

Ethical clearance was obtained from the Ethical Review Committee of Dilla University medical and health Science College. Written informed consent was obtained from each study participant. Strict confidentiality was maintained during the interview process as well as anonymity was kept during data processing and report writing. Food handlers who have found to be positive for enteric pathogens (parasite and bacterial) were referred to their respective staff medical center for appropriate anti-parasitic and antimicrobial treatments.

\section{Results}

\section{Socio demographic characteristics of study participant}


A total of 220 food handlers were included in this study. Of these, $90.9 \%$ were females. The majority of the study participants were between the age group of 20 and 40 years (84.5\%) with the mean age of 31.2 (standard deviation \pm 8.8 years). Of the total respondents, $51.4 \%$ reported that they always perform periodic medical checkups, $81.8 \%$ always trimmed their finger weekly, and $63.2 \%$ always wear a clean apron. Similarly, $69.1 \%$ wear hair garment regularly in their working area and $79.5 \%$ reported that they always use soap and water for hand washing after visiting toilet. The finding from observation also supported that personal hygiene was practiced by the food handlers. From the total, $97.3 \%$ use pipe water for drinking. About $86.8 \%$ of the study participants were drunken unpasteurized milk, while $42.3 \%$ of the study participants eat raw meat (Table 1 ).

\section{ESBL production faecal carriage rate of $E$. coli and $K$. pneumonia from stool culture}

In the present study, The rate of fecal carriage of $E$. coli and $K$. pneumonia among the food handlers of the current study was found to be $146(66.4 \%)$, of which 119 (81.5\%) were E. coli, while 27 (18.5\%) were $K$. pneumonia. From the total bacterial isolates, 37 (25.3\%) were confirmed to be positive for ESBL production. $29(19.9 \%)$ of ESBL producing isolates were E. coli, while K. pneumonia 8(5.5\%) (Fig. 2).

In this study, ESBL-producers and non ESBL producers isolates were predominantly reported in females with a prevalence rates of $35(24.0 \%)$ and $97(66.4 \%)$. E. coli and K. pneumonia producing ESBL were predominantly reported among age group of $20-40$ years with a prevalence of $31(21.2 \%)$. Most of ESBL producers were reported in food handlers who did not attend a regular medical checkup with a prevalence of 25(17.1\%). Majority of E. coli and K. pneumonia producing ESBL were reported among food handlers who did not wash their hands with soap with the prevalence of $24(16.4 \%)$. In the present study, majority of the demographic characteristics study participants have no association with E. coli and K. pneumonia producing ESBL. Only food handlers who used antibiotics in the last 3 months had a strong association with the ESBL carriage with $P$ values of 0.001 (Table 1) 
Table 1

Characteristics of food handlers and faecal carriage rate of ESBLs-producing and non-ESBLs-producing $E$. coli and K. pneumoniae in Dilla University students' cafeteria, Southern Ethiopia $(n=220)$

\begin{tabular}{|c|c|c|c|c|c|c|c|}
\hline \multirow[t]{2}{*}{ Variables } & \multirow[t]{2}{*}{ Category } & \multirow[t]{2}{*}{$\begin{array}{l}\text { Number } \\
\text { tested }\end{array}$} & \multicolumn{2}{|c|}{$\begin{array}{l}\text { Proportion of E. Coli }(\mathrm{n} \\
=119)\end{array}$} & \multicolumn{2}{|c|}{$\begin{array}{l}\text { Proportion of } K \\
\text { pneumonia }(n=27)\end{array}$} & \multirow[t]{2}{*}{$\begin{array}{l}\mathrm{P} \text { - } \\
\text { value }\end{array}$} \\
\hline & & & $\begin{array}{l}\text { ESBLs } \\
\text { positive } \\
(n=29)\end{array}$ & $\begin{array}{l}\text { ESBLs- } \\
\text { negative } \\
(n=90)\end{array}$ & $\begin{array}{l}\text { ESBLs } \\
\text { positive(n } \\
=8)\end{array}$ & $\begin{array}{l}\text { ESBLs- } \\
\text { negative } \\
(n=19)\end{array}$ & \\
\hline \multirow[t]{2}{*}{ Sex } & Male & 20 & $1(0.84 \%)$ & $5(4.2 \%)$ & 1(3.7\%) & $7(25.9 \%)$ & 1 \\
\hline & Female & 200 & $28(23.5 \%)$ & $85(71.4 \%)$ & $7(25.9 \%)$ & $12(44.4 \%)$ & 0.213 \\
\hline \multirow[t]{3}{*}{ Age in year } & $<20$ & 10 & $1(0.84 \%)$ & $28(23.5 \%)$ & 1(3.7\%) & $4(14.8 \%)$ & 1 \\
\hline & $20-40$ & 186 & $26(21.8 \%)$ & 61(51.3\%) & $5(18.5 \%)$ & $9(33.3 \%)$ & 0.121 \\
\hline & $>40$ & 24 & $2(1.7 \%)$ & $18(15.1 \%)$ & $2(7.4 \%)$ & $6(22.2 \%)$ & 0.301 \\
\hline \multirow[t]{2}{*}{ Service year } & $1-5$ year & 38 & $2(1.7 \%)$ & $28(23.5 \%)$ & $3(11.1 \%)$ & $6(22.2 \%)$ & 1 \\
\hline & $>5$ year & 170 & $27(22.7 \%)$ & $62(52.1 \%)$ & $5(18.5 \%)$ & 13(48.1\%) & 0.513 \\
\hline \multirow{2}{*}{$\begin{array}{l}\text { Medical } \\
\text { Checkups }\end{array}$} & Yes & 113 & $9(7.6 \%)$ & $31(26.1 \%)$ & $3(11.1 \%)$ & $8(29.6 \%)$ & 1 \\
\hline & No & 107 & $20(16.8 \%)$ & $59(49.6 \%)$ & $5(18.5 \%)$ & $11(40.7 \%)$ & 0.08 \\
\hline \multirow{2}{*}{$\begin{array}{l}\text { Hands } \\
\text { washing habit }\end{array}$} & Yes & 216 & $28(23.5 \%)$ & $83(69.7 \%)$ & $6(22.2 \%)$ & 15(55.6\%) & 1 \\
\hline & No & 4 & $1(0.84 \%)$ & $7(5.9 \%)$ & $2(7.4 \%)$ & $4(14.8 \%)$ & 0.612 \\
\hline \multirow{2}{*}{$\begin{array}{l}\text { Finger nail } \\
\text { status }\end{array}$} & Trimmed & 180 & $24(20.2 \%)$ & $60(50.4 \%)$ & $5(18.5 \%)$ & $13(48.1 \%)$ & 1 \\
\hline & $\begin{array}{l}\text { Not } \\
\text { trimmed }\end{array}$ & 40 & $5(4.2 \%)$ & $30(25.2 \%)$ & $3(11.1 \%)$ & $6(22.2 \%)$ & 0.341 \\
\hline \multirow{2}{*}{$\begin{array}{l}\text { Antibiotics } \\
\text { used in the } \\
\text { last 3months }\end{array}$} & Yes & 139 & $27(22.7 \%)$ & $58(48.7 \%)$ & $7(25.9 \%)$ & $12(44.4 \%)$ & $0.001 *$ \\
\hline & No & 81 & $2(1.7 \%)$ & $32(26.9 \%)$ & 1(3.7\%) & $7(25.9 \%)$ & 1 \\
\hline \multirow{2}{*}{$\begin{array}{l}\text { Wear hair } \\
\text { garment }\end{array}$} & Yes & 152 & $22(18.5 \%)$ & $48(40.3 \%)$ & $6(22.2 \%)$ & $14(51.9 \%)$ & 0.53 \\
\hline & No & 68 & 7(5.9\%) & $42(35.3 \%)$ & $2(7.4 \%)$ & $5(18.5 \%)$ & 1 \\
\hline \multirow[t]{2}{*}{$\begin{array}{l}\text { Hands wash } \\
\text { with soap }\end{array}$} & $\begin{array}{l}\text { Only } \\
\text { with } \\
\text { water }\end{array}$ & 45 & $18(15.1 \%)$ & $15(12.6 \%)$ & $6(22.2 \%)$ & $3(11.1 \%)$ & 0.154 \\
\hline & $\begin{array}{l}\text { With } \\
\text { soap }\end{array}$ & 175 & $11(9.2 \%)$ & 75(63.1\%) & $2(7.4 \%)$ & 16(59.3\%) & 1 \\
\hline \multirow{3}{*}{$\begin{array}{l}\text { Source of } \\
\text { water for } \\
\text { drinking }\end{array}$} & Pipe & 214 & $28(23.5 \%)$ & 78(65.5\%) & $5(18.5 \%)$ & $12(44.4 \%)$ & 1 \\
\hline & $\begin{array}{l}\text { Hand } \\
\text { dug well }\end{array}$ & 25 & $1(0.84 \%)$ & $9(7.5 \%)$ & $2(7.4 \%)$ & $5(18.5 \%)$ & 0.301 \\
\hline & Other & 195 & $28(23.5 \%)$ & $3(2.5 \%)$ & 1(3.7\%) & $2(7.4 \%)$ & 0.462 \\
\hline
\end{tabular}




\begin{tabular}{|llllllll|}
$\begin{array}{l}\text { Unpasteurized } \\
\text { milk }\end{array}$ & Yes & 29 & $1(0.84 \%)$ & $9(7.6 \%)$ & $2(7.4 \%)$ & $5(18.5 \%)$ & 1 \\
\cline { 2 - 7 } & No & 191 & $28(23.5 \%)$ & $81(68.1 \%)$ & $6(22.2 \%)$ & $14(51.9 \%)$ & 0.211 \\
\hline $\begin{array}{l}\text { Eating raw } \\
\text { meat }\end{array}$ & Yes & 93 & $11(9.2 \%)$ & $40(33.6 \%)$ & $3(11.1 \%)$ & $6(22.2 \%)$ & 1 \\
\cline { 2 - 7 } & No & 127 & $18(15.1 \%)$ & $50(42.1 \%)$ & $5(18.5 \%)$ & $13(48.1 \%)$ & 0.412 \\
\hline
\end{tabular}

\section{Antimicrobial resistance pattern of ESBL-Producing and Non-ESBL Producing E. coli and $K$. pneumonia}

In the current study, ESBL-producing isolates showed significantly higher resistance not only towards the third generation cephalosporins but also towards other antimicrobial agents tested $(p>0.001)$. Both $E$. coli and K. pneumonia ESBL producers were highly resistant to Aztreonam, cefotaxime, ceftriaxone, cefuroxime, and ceftazidime with resistance rates ranged from 87-100\%. Almost all ESBL-producing and non-ESBL-producing isolates were highly resistant to ampicillin and tetracycline with a resistance rate of $89.5 \%$. Higher resistance rate of ESBL producing isolate was also reported among ciprofloxacin, trimethoprim-sulfamethoxazole, and nitrofurantoin with resistance rate ranged from $67-75 \%$. In the current study, imipenem was the least resistant antibiotic against ESBL producing isolates with a resistant rate of $13.8 \%$ (Table 2 ). 
Table 2

Antimicrobial resistance patterns of ESBLs positive and ESBLs-negative E. coli and k. pneumonia isolated from food handlers in Dilla University student cafeteria, Southern Ethiopia $(\mathrm{n}=220)$

\begin{tabular}{|c|c|c|c|c|c|}
\hline \multirow[b]{2}{*}{ Antibiotics } & \multirow[b]{2}{*}{ Pattern } & \multicolumn{2}{|c|}{$\begin{array}{l}\text { Antimicrobial resistance } \\
\text { pattern of } E \text {. Coli }(n=119)\end{array}$} & \multicolumn{2}{|c|}{$\begin{array}{l}\text { Antimicrobial resistance pattern of } \\
\text { K. pneumonia( } n=27)\end{array}$} \\
\hline & & $\begin{array}{l}\text { ESBLs positive } \\
(n=29)\end{array}$ & $\begin{array}{l}\text { ESBLs- } \\
\text { negative } \\
(n=90)\end{array}$ & $\begin{array}{l}\text { ESBLs positive } \\
(n=8)\end{array}$ & $\begin{array}{l}\text { ESBLs-negative } \\
(n=19)\end{array}$ \\
\hline \multirow[t]{2}{*}{ Ampicillin } & $S$ & $0(0.0 \%)$ & $20(22.2 \%)$ & $0(0.0 \%)$ & $2(10.5 \%)$ \\
\hline & $\mathrm{R}$ & $29(100 \%)$ & 70(77.8\%) & $8(100 \%)$ & 17(89.5\%) \\
\hline \multirow[t]{2}{*}{ Aztreonam } & S & $1(3.4 \%)$ & $6(6.7 \%)$ & $1(12.5 \%)$ & $2(10.5 \%)$ \\
\hline & $\mathrm{R}$ & $28(96.6 \%)$ & 84(93.7\%) & $7(87.5 \%)$ & 17(89.5\%) \\
\hline \multirow[t]{2}{*}{ Cefotaxime } & $S$ & $1(3.4 \%)$ & $7(7.8 \%)$ & $0(0.0 \%)$ & $2(10.5 \%)$ \\
\hline & $\mathrm{R}$ & $28(96.6 \%)$ & $83(92.2 \%)$ & $8(100 \%)$ & 17(89.5\%) \\
\hline \multirow[t]{2}{*}{ Cefuroxime } & S & $2(6.9 \%)$ & $6(6.7 \%)$ & $1(12.5 \%)$ & $2(10.5 \%)$ \\
\hline & $\mathrm{R}$ & 27(93.1\%) & 84(93.7\%) & $7(87.5 \%)$ & 17(89.5\%) \\
\hline \multirow[t]{2}{*}{ Ceftazidime } & $S$ & $0(0.0 \%)$ & $6(6.7 \%)$ & $0(0.0 \%)$ & $2(10.5 \%)$ \\
\hline & $\mathrm{R}$ & $29(100 \%)$ & 84(93.3\%) & $8(100 \%)$ & 17(89.5\%) \\
\hline \multirow[t]{2}{*}{ Ceftriaxone } & $S$ & $1(3.4 \%)$ & $13(14.4 \%)$ & $1(12.5 \%)$ & $6(31.6 \%)$ \\
\hline & $\mathrm{R}$ & $28(96.6 \%)$ & 77(85.6\%) & $7(87.5 \%)$ & $13(68.4 \%)$ \\
\hline \multirow[t]{2}{*}{ Ciprofloxacin } & S & $9(31.0 \%)$ & $29(32.2 \%)$ & $2(25.0 \%)$ & $5(26.3 \%)$ \\
\hline & $\mathrm{R}$ & $20(69.0 \%)$ & $61(67.8 \%)$ & $6(75.0 \%)$ & 14(73.7\%) \\
\hline \multirow[t]{2}{*}{ Imipenem } & $S$ & $25(86.2 \%)$ & $68(75.6 \%)$ & $7(87.5 \%)$ & 14(73.7\%) \\
\hline & $\mathrm{R}$ & $4(13.8 \%)$ & $22(24.4 \%)$ & $1(12.5 \%)$ & $5(26.3 \%)$ \\
\hline \multirow[t]{2}{*}{ Nitrofurantoin } & $S$ & $9(31.0 \%)$ & $29(32.2 \%)$ & $2(25.0 \%)$ & $5(26.3 \%)$ \\
\hline & $\mathrm{R}$ & $20(69.0 \%)$ & $61(67.8 \%)$ & $6(75.0 \%)$ & 14(73.7\%) \\
\hline \multirow[t]{2}{*}{ Tetracycline } & S & $1(3.4 \%)$ & $5(5.6 \%)$ & $0(0.0 \%)$ & $2(10.5 \%)$ \\
\hline & $\mathrm{R}$ & $28(96.6 \%)$ & $85(94.4 \%)$ & $8(100 \%)$ & 17(89.5\%) \\
\hline \multirow{2}{*}{$\begin{array}{l}\text { Trimethoprim } \\
\text { sulfamethoxazol }\end{array}$} & $S$ & $9(31.0 \%)$ & $29(32.2 \%)$ & $2(25.0 \%)$ & $5(26.3 \%)$ \\
\hline & $\mathrm{R}$ & $20(69.0 \%)$ & $61(67.8 \%)$ & $6(75.0 \%)$ & 14(73.7\%) \\
\hline
\end{tabular}




\section{Antibiogram pattern of multidrug resistant $E$. coli and $K$. pneumoniae}

In this study, around 34(91.9\%) of ESBL-producing isolates were resistance to both $\beta$-lactam groups and tetracycline, while $26(70.3 \%)$ of ESBL-producing isolates were co-resistant to $\beta$-lactams groups and ciprofloxacin and $20(54.1 \%)$ of ESBL producers were resistant to both $\beta$-lactams groups and trimethoprim sulfamethoxazole. Others ESBL-producing isolates were co-resistant to $\beta$-lactams groups, and 3,4 , and 5 types of non- $\beta$ lactam antibiotics with a resistant rates of $17(45.9 \%), 12(32.4 \%)$, and $8(21.6 \%)$, respectively (Table 3).

Table 3

Multidrug resistance pattern of E. coli and K. pneumonia faecal carriage isolated from food handlers in Dilla University student cafeteria, Southern Ethiopia $(n=220)$

\begin{tabular}{|llll|}
\hline Antibiotics categories & E. coli $(\mathbf{n = 2 9 )}$ & K. pneumonia $(\mathbf{n = 8})$ & $\begin{array}{l}\text { Total MDR rate } \\
(\mathbf{n}=\mathbf{3 7})\end{array}$ \\
\hline$\beta$-lactams + TET & $27(93.1 \%)$ & $7(87.5 \%)$ & $34(91.9 \%)$ \\
\hline$\beta$-lactams + TET, CIP & $20(69.0 \%)$ & $6(75.0 \%)$ & $26(70.3 \%)$ \\
\hline$\beta$-lactams + TET, SXT & $15(51.7 \%)$ & $5(62.5 \%)$ & $20(54.1 \%)$ \\
\hline$\beta$-lactams + TET, SXT, CIP & $13(44.8 \%)$ & $4(50.0 \%)$ & $17(45.9 \%)$ \\
\hline$\beta$-lactams + TET, SXT, NIT, CIP & $9(31.0 \%)$ & $3(37.5 \%)$ & $12(32.4 \%)$ \\
\hline$\beta$-lactams + CIP, IM, NIT, TET, SXT & $6(20.7 \%)$ & $2(25.0 \%)$ & $8(21.6 \%)$ \\
\hline $\begin{array}{l}\text { Beta-lactams groups: (Ampicillin, Cefotaxime, Cefuroxime, Ceftazidime, Ceftriaxone); CIP: } \\
\text { Ciprofloxacin; IM: Imipenem; NIT: Nitrofurantoin; TET: Tetracycline, SXT: Trimethoprim } \\
\text { sulfamethoxazole }\end{array}$ & & & \\
\hline
\end{tabular}

\section{Discussion}

The emergence and rapid spread of multidrug resistance strains of ESBL producing Enterobacteriaceae is a serious public health issue worldwide. Rapid expansion of ESBLs highly affects the activity of broadspectrum antibiotics, creating major therapeutic difficulties with a significant impact on the outcomes for patients (25). Although it was suspected to be high, few data are available on the prevalence of faecal carriage of ESBL producing Enterobacteriaceae and little attention was given to it in Africa. In this study, we examined the faecal carriage rate of ESBL producers E. coli or K. pneumoniae in food handlers working at the Dilla University student cafeteria.

The phenotypic information obtained in the current study indicates a significant prevalence of ESBL producers. The overall magnitude of faecal carriage of ESBL producing E. coli or K. pneumoniae among apparently health food handlers was $25.3 \%$. This indicates a remarkable high number of ESBL productions among food handlers working in food preparation. Our finding is consistent with studies 
conducted in India (26), Italy (27), Egypt (28) and in Turkey (29) with prevalence ranged from 15-33\%. However, it is lower than the study conducted in Central African (30), Tanzania (31), Nigeria (32), Burkina Faso (33) and Ghana (34) with prevalence ranged from $40-59 \%$. The variation might be explained by methodological differences, differences in study area, quality of media used, type of specimen collected. The use of low quality, inappropriate use of antibiotics, and weak infection prevention measures may additionally make a contribution to the high magnitude of ESBL production.

In the present study, E. coli was the leading faecal carriage of ESBL producing Enterobacteriaceae with a prevalence of $19.9 \%$, followed by $K$. pneumonia (5.5\%). Our finding agrees with studies conducted in India $(26,27)$, Central African (30), Central India (35) and Burkina Faso (33), where E. coli was the predominant ESBL producer than K. pneumonia. However, study conducted in Uganda (36), Gambia (37) and elsewhere (38) reported a higher prevalence of K. pneumonia than E. coli. Those bacteria can result in the transfer of the resistance genes to other strains of $E$. coli and $K$. pneumonia within the gastrointestinal tract that can result in fatal consequences. In addition, when those carriers admitted to hospitals they can easily transmit the infection to other hospitalized patients. Quick adaptation of those strains to the harsh environment, upregulation of intrinsic resistance mechanisms, and rapid acquisition and transferring of drug resistance genes through mobile genetic elements could be a possible explanation for an elevated overall drug resistance prevalence rate against different categories of drugs.

In the current study, the faecal carriage of ESBLs among food-handlers working in the cafeteria was significantly associated with food handlers who used antibiotics repeatedly in the last 3months and those food handlers who did not attend regular medical check studies $(39,40)$. In most parts of developing countries including Ethiopia, antibiotics were used without prescription which can lead to overuse or misuse of antibiotics. This can contribute to the emergence and spread of antimicrobial-resistant strains. Moreover, in developing countries, poor personal hygiene practices may increase the prevalence of bacterial gastrointestinal infections which may play a role in rising antimicrobial resistance. This increases the risk of treatment failure with potentially serious consequences. This can be overcome by performing bacterial culture and performing an antimicrobial susceptibility test to select the most effective antibiotics for suspected cases of gastrointestinal infected patients.

In the present study, ESBL-Producing E. coli and K. pneumonia were highly resistant to ampicillin, cefotaxime, aztreonam, ceftazidime, and ceftriaxone with resistance rates ranged from $88-100 \%$, while the least resistant was found against imipenem with resistance rate $13.8 \%$. Our finding agrees with studies conducted in Gambia ((41) Burkina Faso (33), Ghana (34), Saudi Arabia (42), Israel (43), Poland (44), and Sierra Leone (45). This indicates ESBL-producing enterobacteriaceae were rapidly emerging in developing and developed countries. In this study, ESBL-producing E. coli and $K$. pneumonia were not only resistance to third-generation cephalosporins but also to other non- $\beta$ lactams groups of antibiotics. The finding of this study showed that Imipenem had a better performance against ESBL-Producing enterobacteriaceae than other antibiotics including cephalosporin group. This is inconsistent with study conducted by Moges and his colleagues (46) who reported that imipenem had higher performance for the treatment of ESBLProducing Enterobacteriaceae. 
Our findings showed that greater than $90 \%$ of the ESBL producing isolates were MDR. The MDR nature of ESBL-producing E. coli and K. pneumonia may be explained by the fact that they are plasmid-mediated enzymes which are carrying multi-resistant genes by plasmid, transposon, and integron and they are readily transferred to other bacteria through conjugation, transduction or transformation. The carrier of those bacteria can easily disseminate to the community and hospitalized patient which can result in remarkable consequences. As a result, now a days bacteria with multiple resistances to antibiotics are widely distributed in hospitals and communities and became a serious problem throughout the world (47). This is the most challenging and alarming condition in the management of infectious diseases associated with ESBL producing Entrobacteriaceae.

\section{Limitations Of The Study}

The limitations of this study were the lack of a molecular confirmatory test to establish genotypes of ESBLs. The participants were unable to provide the previous prescribed antibiotics to show association with the faecal carriage of ESBLs (recall bias). Most of the study participants were female, which tends to show the gender bis.

\section{Conclusion}

In this study, the magnitude of faecal carriage of ESBL-producing E. coliand K. pneumonia is alarmingly high and threat to human health. ESBL-producing faecal carriage showed high resistance to aztreonam, cefotaxime, ceftriaxone, cefuroxime, and ceftazidime. The better option for the treatment of ESBLproducing E. coli and K. pneumonia in this study is imipenem. The occurrence of multidrug resistance to third-generation cephalosporins and non- $\beta$ lactam antibiotics is more common among ESBL producers. In the present study, ESBL-producing isolates were co-resistant to $\beta$-lactams antibiotics plus at least one of the non $\beta$-lactam antibiotics. Only food handlers who used antibiotics repeatedly in the last 3 months were significantly associated with the ESBL faecal carriage. The rise of ESBL-producing Enterobacteriaceae requires strict infection prevention and control strategies and strengthening of the diagnostic capacity of laboratory professionals for the detection and surveillance of antibiotic resistance that have a significant role in clinical decision-making. Hence a coordinated effort should be implemented.

\section{Declarations}

\section{Acknowledgements:}

The authors would like to acknowledge Dilla University for funding and providing the necessary materials to conduct this research work. I acknowledge Dilla University food and nutrition research center, Laboratory Department staff and all study participants for their cooperation during sample collection

\section{Additional information:}

All data relevant to the study are included in the article 


\section{Ethics approval:}

Ethical clearance was obtained from the Research and Ethical Review Committee and approved by the Institutional Review Board, Dilla University. Permission was also obtained from Dilla University Human Resource Directorate.

\section{Consent:}

Consent was obtained from each participant or guardian as incorporated in the "participant information sheet" before inclusion in this study. Written informed consent and assent were obtained from the study subjects before data collection.

\section{Data availability statement:}

All data relevant to the study are included in the article.

\section{Conflicts of Interest:}

The authors declare that they have no conflicts of interest

\section{Funding:}

This work was supported by Dilla University, Food and Nutrition Research Center

\section{Authors' contributions:}

$K D$ is the first and corresponding author. $K D$ and EA conceived and designed the study. KD, EA, $L T$, and ZA acquired the data. KD and EA analyzed the data and interpreted the results. KD, EA and ZA drafted the initial and final manuscripts. KD, EA and LT performed critical revisions of the manuscript. All authors approved the final version of the manuscript.

\section{References}

1. Chiu C-W, Li M-C, Ko W-C, Li C-W, Chen P-L, Chang C-M, et al. Clinical impact of Gram-negative nonfermenters on adults with community-onset bacteremia in the emergency department. Journal of Microbiology, Immunology and Infection. 2015;48(1):92-100.

2. Ventola CL. The antibiotic resistance crisis: part 1: causes and threats. Pharmacy and therapeutics. 2015;40(4):277.

3. Gelband H, Molly Miller P, Pant S, Gandra S, Levinson J, Barter D, et al. The state of the world's antibiotics 2015. Wound healing southern africa. 2015;8(2):30-4

4. de La Blanchardière A, Dargère S, Guérin F, Daurel C, Saint-Lorant G, Verdon R, et al. Non-carbapenem therapy of urinary tract infections caused by extended-spectrum $\beta$-lactamase-producing Enterobacteriaceae. Medecine et maladies infectieuses. 2015;45(5):169-72. 
5. Health UDo, Services H. Antibiotic resistance threats in the United States, 2013. Centers for disease control and prevention. 2013:1-113.

6. Kakati B, Agarwal S, Gupta S. Emerging issues regarding management of MDR Non-Fermenting Gram Negative ventilator associated pneumonia in a Rural Catering Tertiary Care Hospital. J Med Sci Clin Res. 2015;4:13232-8

7. Nordmann P, Naas T, Poirel L. Global spread of carbapenemase-producing Enterobacteriaceae. Emerging infectious diseases. 2011;17(10):1791.

8. Paterson DL. Resistance in gram-negative bacteria: Enterobacteriaceae. American journal of infection control. 2006;34(5):S20-S8.

9. Dogan A, Lasch P, Neuschl C, Millrose MK, Alberts R, Schughart K, et al. ATR-FTIR spectroscopy reveals genomic loci regulating the tissue response in high fat diet fed BXD recombinant inbred mouse strains. BMC genomics. 2013;14(1):386.

10. Aiken AM, Mturi N, Njuguna P, Mohammed S, Berkley JA, Mwangi I, et al. Risk and causes of paediatric hospital-acquired bacteraemia in Kilifi District Hospital, Kenya: a prospective cohort study. The Lancet. 2011;378(9808):2021-7.

11. Abdallah H, Wintermans B, Reuland E, Koek A, Al Naiemi N, Ammar A, et al. Extended-spectrum $\beta$ lactamase-and carbapenemase-producing Enterobacteriaceae isolated from Egyptian patients with suspected blood stream infection. PloS one. 2015;10(5).

12. McDonald M, Blondeau JM. Emerging antibiotic resistance in ocular infections and the role of fluoroquinolones. Journal of Cataract \& Refractive Surgery. 2010;36(9):1588-98.

13. Organization WH. Antimicrobial resistance: global report on surveillance: World Health Organization; 2014.

14. Duthey B. Priority Medicines for Europe and the World" A public health approach to innovation. WHO Background paper. 2013;6.

15. Fournier $P E$, Richet $H$, Weinstein RA. The epidemiology and control of Acinetobacter baumannii in health care facilities. Clinical infectious diseases. 2006;42(5):692-9.

16. Bassetti M, Ginocchio F, Mikulska M. New treatment options against gram-negative organisms. Annual Update in Intensive Care and Emergency Medicine 2011: Springer; 2011. p. 501-15.

17. Paterson DL, Bonomo RA. Extended-spectrum $\beta$-lactamases: a clinical update. Clinical microbiology reviews. 2005;18(4):657-86.

18. Pitout JD, Laupland KB. Extended-spectrum $\beta$-lactamase-producing Enterobacteriaceae: an emerging public-health concern. The Lancet infectious diseases. 2008;8(3):159-66.

19. Alvarez-Uria G, Gandra S, Mandal S, Laxminarayan R. Global forecast of antimicrobial resistance in invasive isolates of Escherichia coli and Klebsiella pneumoniae. International Journal of Infectious Diseases. 2018;68:50-3

20. Murray TS, Peaper DR. The contribution of extended-spectrum $\beta$-lactamases to multidrug-resistant infections in children. Current opinion in pediatrics. 2015;27(1):124-31. 
21. Bevan ER, Jones AM, Hawkey PM. Global epidemiology of CTX-M $\beta$-lactamases: temporal and geographical shifts in genotype. Journal of antimicrobial chemotherapy. 2017;72(8):2145-55.

22. Bush K, Jacoby GA. Updated functional classification of $\beta$-lactamases. Antimicrobial agents and chemotherapy. 2010;54(3):969-76.

23. Testing ECOAS. Data from the EUCAST MIC distribution website. European Committee on Antimicrobial Susceptibility Testing Data from the EUCAST MIC distribution website, last accessed 09 May 2013. 2016

24. Drieux L, Brossier F, Sougakoff W, Jarlier V. Phenotypic detection of extended-spectrum $\beta$-lactamase production in Enterobacteriaceae: review and bench guide. Clinical Microbiology and Infection. 2008;14:90-103.

25. Adler A, Katz DE, Marchaim D. The continuing plague of extended-spectrum $\beta$-lactamase-producing Enterobacteriaceae infections. Infectious Disease Clinics. 2016;30(2):347-75.

26. Indernath S, Priyadharsini RI, Manikkanan M, Babu SV. Prevalence and phenotypic characterization of ESBL producing E. coli and Klebsiella among the fecal isolates of normal population.

27. Rao SP, Rama PS, Gurushanthappa V, Manipura R, Srinivasan K. Extended-spectrum beta-lactamases producing Escherichia coli and Klebsiella pneumoniae: A multi-centric study across Karnataka. Journal of laboratory physicians. 2014;6(1):7

28. Fam N, Leflon-Guibout V, Fouad S, Aboul-Fadl L, Marcon E, Desouky D, et al. CTX-M-15-producing Escherichia coli clinical isolates in Cairo (Egypt), including isolates of clonal complex ST10 and clones ST131, ST73, and ST405 in both community and hospital settings. Microbial Drug Resistance. 2011;17(1):67-73.

29. Nijssen S, Florijn A, Bonten M, Schmitz F, Verhoef J, Fluit A. Beta-lactam susceptibilities and prevalence of ESBL-producing isolates among more than 5000 European Enterobacteriaceae isolates. International journal of antimicrobial agents. 2004;24(6):585-91.

30. Girlich D, Bouihat N, Poirel L, Benouda A, Nordmann P. High rate of faecal carriage of extendedspectrum $\beta$-lactamase and OXA-48 carbapenemase-producing Enterobacteriaceae at a university hospital in Morocco. Clinical Microbiology and Infection. 2014;20(4):350-4.

31. Moyo SJ, Aboud S, Kasubi M, Lyamuya EF, Maselle SY. Antimicrobial resistance among producers and non-producers of extended spectrum beta-lactamases in urinary isolates at a tertiary Hospital in Tanzania. BMC research notes. 2010;3(1):348.

32. Ogefere HO, Aigbiremwen PA, Omoregie R. Extended-spectrum beta-lactamase (ESBL)-producing Gram-negative isolates from urine and wound specimens in a tertiary health facility in southern Nigeria. Tropical Journal of Pharmaceutical Research. 2015;14(6):1089-94.

33. Ouedraogo A-S, Sanou M, Kissou A, Sanou S, Solaré H, Kaboré F, et al. High prevalence of extendedspectrum ß-lactamase producing enterobacteriaceae among clinical isolates in Burkina Faso. BMC infectious diseases. 2016;16(1):326.

34. Obeng-Nkrumah N, Twum-Danso K, Krogfelt KA, Newman MJ. High levels of extended-spectrum betalactamases in a major teaching hospital in Ghana: the need for regular monitoring and evaluation of 
antibiotic resistance. The American journal of tropical medicine and hygiene. 2013;89(5):960-4.

35. Alfola MMHR, Kamel Z, Nada MGED, Rashed LA, El-Awady BA. Phenotypic and Genotypic Characterization of ESBL-Producing Escherichia coli and Klebsiella pneumonia isolates from Patient's Urine specimens. The International Arabic Journal of Antimicrobial Agents. 2017;6(4).

36. Kateregga JN, Kantume R, Atuhaire C, Lubowa MN, Ndukui JG. Phenotypic expression and prevalence of ESBL-producing Enterobacteriaceae in samples collected from patients in various wards of Mulago Hospital, Uganda. BMC pharmacology and Toxicology. 2015;16(1):14.

37. Sanneh B, Kebbeh A, Jallow HS, Camara Y, Mwamakamba LW, Ceesay IF, et al. Prevalence and risk factors for faecal carriage of Extended Spectrum $\beta$-lactamase producing Enterobacteriaceae among food handlers in lower basic schools in West Coast Region of The Gambia. PLoS One. 2018;13(8):e0200894.

38. Abera B, Kibret M, Mulu W. Extended-Spectrum beta ( $\beta$ )-lactamases and Antibiogram in Enterobacteriaceae from clinical and drinking water Sources from Bahir Dar City, Ethiopia. PloS one. 2016;11(11).

39. Calbo E, Romaní V, Xercavins M, Gómez L, Vidal CG, Quintana S, et al. Risk factors for communityonset urinary tract infections due to Escherichia coli harbouring extended-spectrum $\beta$-lactamases. Journal of Antimicrobial Chemotherapy. 2006;57(4):780-3

40. Briongos-Figuero L, Gómez-Traveso T, Bachiller-Luque P, Domínguez-Gil González M, Gómez-Nieto A, Palacios-Martín T, et al. Epidemiology, risk factors and comorbidity for urinary tract infections caused by extended-spectrum beta-lactamase (ESBL)-producing enterobacteria. International journal of clinical practice. 2012;66(9):891-6.

41. Okomo UA. Neonatal Infections; a hospital-based study in The Gambia examining aetiology and associated maternal Colonisation: London School of Hygiene \& Tropical Medicine; 2018.

42. Alyamani EJ, Khiyami AM, Booq RY, Majrashi MA, Bahwerth FS, Rechkina E. The occurrence of ESBLproducing Escherichia coli carrying aminoglycoside resistance genes in urinary tract infections in Saudi Arabia. Annals of clinical microbiology and antimicrobials. 2017;16(1):1.

43. Schwaber MJ, Navon-Venezia S, Schwartz D, Carmeli Y. High levels of antimicrobial coresistance among extended-spectrum- $\beta$-lactamase-producing Enterobacteriaceae. Antimicrobial agents and chemotherapy. 2005;49(5):2137-9.

44. Esiobu N, Armenta L, Ike J. Antibiotic resistance in soil and water environments. International Journal of Environmental Health Research. 2002;12(2):133-44.

45. Leski TA, Taitt CR, Bangura U, Stockelman MG, Ansumana R, Cooper WH, et al. High prevalence of multidrug resistant Enterobacteriaceae isolated from outpatient urine samples but not the hospital environment in Bo, Sierra Leone. BMC infectious diseases. 2016;16(1):167.

46. Moges F, Setegn Eshetie WA, Mekonnen F, Dagnew M, Endale A, Amare A, et al. High prevalence of extended-spectrum beta-lactamase-producing Gram-negative pathogens from patients attending Felege Hiwot Comprehensive Specialized Hospital, Bahir Dar, Amhara region. PloS one. 2019;14(4). 
47. Jacoby GA, Medeiros AA. More extended-spectrum beta-lactamases. Antimicrobial agents and chemotherapy. 1991;35(9):1697.

\section{Figures}
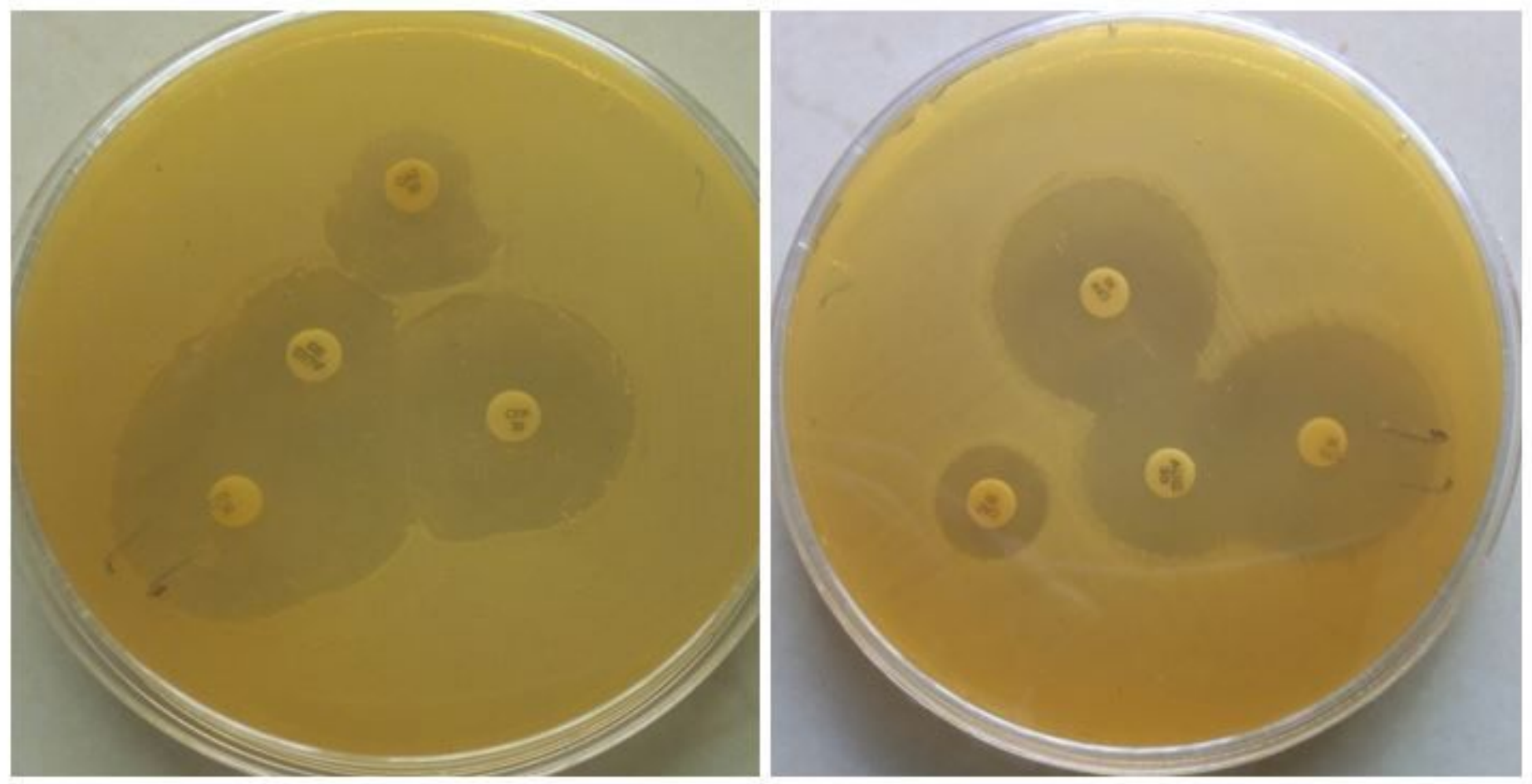

\section{Figure 1}

The phenotypic confirmation test of ESBL producers performed using double disc synergy between amoxicillin-clavulanic acid and cefotaxime, ceftazidime, and aztreonam on Mueller-Hinton agar plate. 


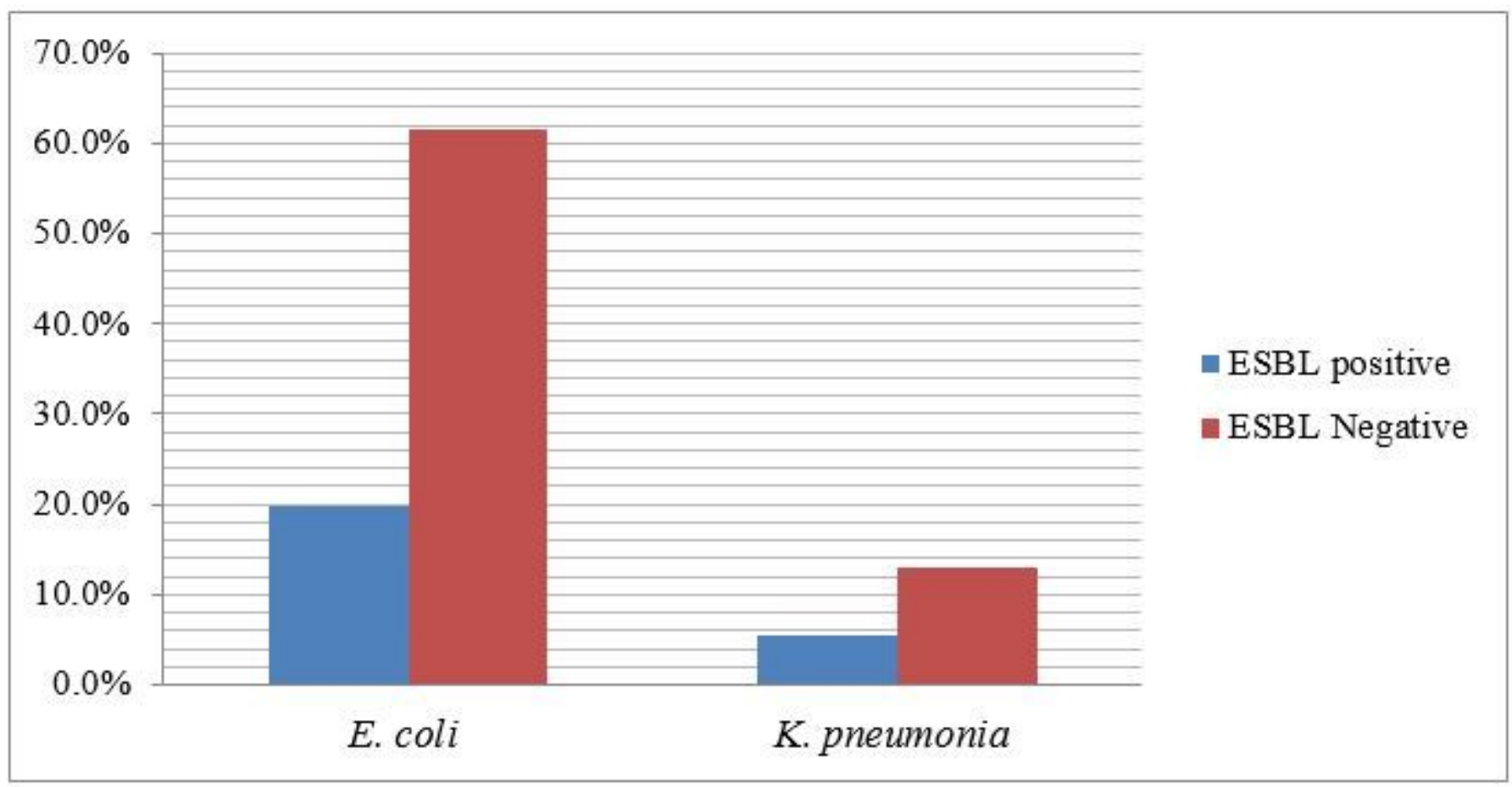

Figure 2

The distribution of ESBL-producing E. coli and K. pneumoniae isolated from stool of apparently health food handlers 